\title{
Erratum: «Ferroelectric smectic C* phase with sub-wavelength helix pitch induced in a nematic liquid crystal by chiral non-mesogenic dopants» [Journal Liquid Crystals and their Application, 20 (3), 26-33 (2020) DOI: $10.18083 /$ LCAppl.2020.3.26]
}

\section{E.P. Pozhidaevi,2, S.I. Torgova1, E.M. Budynina ${ }^{1,3}$, T.P. Tkachenko ${ }^{1,2}$, A.V. Kuznetsov ${ }^{1,2}$, V.A. Barbashov ${ }^{1}$}

${ }^{1}$ P. N. Lebedev Physical Institute, 53 Leninsky Pr., Moscow, 119991, Russia

${ }^{2}$ Moscow Aviation Institute (National Research University), 4 Volokolamskoe Sh., Moscow, 125993, Russia ${ }^{3}$ Lomonosov Moscow State University, Department of Chemistry, 1-3 Leninskie gory, Moscow, 119991, Russia E-mail: epozhidaev@mail.ru

Two additional references [17] and [18] were added:

[17] Mikhailenko V.V., Popova E.V., Gamzaeva S.A., Pozhidaev E.P., Vashchenko V.V. Induced helical nanostructures in ferroelectric liquid crystals. Intern. Research and Practice Conf. «Nanotechnology and nanomaterials (NANO-2016)». Abstract book. Ukraine, Lviv, 24-27 August, 2016, p. 610.

[18] Patent of Ukraine UA № 119903 C2. Bis ((S)-1-(((S)-alkan-2-yloxy)carbonyl)ethyl)-4,4”terphenyldicarboxylate bis(S)-1-(((R)-alkan-2-yloxy)carbonyl)ethyl)-4,4"-terphenyldicarboxylate ferroelectric liquid crystal compositions / A.I. Krivoshey, V.V. Mikhailenko, V.V. Vashchenko; request № a 2017 08371; declared 14.08.2017; publ. 27.08.2019; Bull. «Industrial Property» № 16, 19 p. (in Ukrainian).

Therefore, the reference numbers in the text and reference list were shifted: starting from the reference [17] (it became now [19]) and so on.

These corrections do not affect the conclusion of the article. The article has been corrected online. The revised version of the article is available on https://doi.org/10.18083/LCAppl.2020.3.26

DOI: 10.18083/LCAppl.2020.4.99 